\title{
The Gordian knot: Regulatory relationship and legal education.
}

Paul Maharg

Symbolic control, through its pedagogic modalities, attempts to shape and distribute forms of consciousness, identity and desire. ${ }^{1}$

Regulators must facilitate and encourage, not just accredit and monitor. ${ }^{2}$

\begin{abstract}
This article is a version of themes presented at a plenary lecture given at the 2016 Legal Education Conference at the Chinese University of Hong Kong. Regulation of legal education is becoming increasingly important as regulation becomes more complex and intrusive in educational design and practice. As a consequence of pressures upon regulators from government, consumer groups, educational institutions, the profession and other stakeholders there has been an increase in the number and size of reports and reviews as regulators and accreditors seek to position and re-position their practices within the regulatory field. In that field regulatory relationship is one aspect of the regulation of legal education that is insufficiently researched and understood. This article seeks to explore models by which the relationship between regulators and legal educators can be improved. It begins by summarising some of the regulatory literature on legal education, and suggesting that a complexity theory approach in safety regulation could be used in legal education. An example of regulatory relationship between educational institution and regulator will be described and aspects analysed; and in the final section I outline possible ways forward for regulators and legal educators.
\end{abstract}

\section{Introduction}

\section{Legal education regulation}

Regulation is a complex, socially-pervasive field of activity in industrialised economies. It takes many forms, and while regulation theory and practice is not uniform, there is a certain convergence around regulatory domains that regulators, particularly those of professional activities, are engaged in. These domains often include the control of risk, the creation and management of compliance regimes, the protection of consumer interests, and the monitoring of performance and outcomes cultures. $^{3}$ At a meta-level it includes the management of the processes of regulation and deregulation itself by which a regulator's activities are authorised and implemented. ${ }^{4}$ Recently a group of regulatory strategies have come to be adopted as alternatives to more adversarial command-and-control regimes. ${ }^{5}$ These include risk-based regulation, meta-regulation, principles-

\footnotetext{
${ }^{1}$ Basil Bernstein \& Joseph Solomon, "Pedagogy, Identity and the Construction of a Theory of Symbolic Control": Basil Bernstein questioned by Joseph Solomon, 20 BRITISH JOURNAL OF SOCIOLOGY OF EDUCATION 265-279 (1999), 269.

2 Julian Webb et al., Setting Standards. The Future of Legal Services Education and Training Regulation in England and Wales (SRA, BSB, IPS) (2013)

3 Insert here definition of risk-based regulation from LETR p.87 no.16.

4 In the Legal Education and Training Report we dealt with many such issues, and my views, on both regulated and unregulated sectors of the profession, have not changed since we wrote the report. ${ }^{4} I d$. at 264.

${ }^{5}$ See Regulation: After command and control, in The Human Face of LaW: EsSays in Honour of Donald Harris (K. Hawkins ed. 1997) 45-73.
} 
based regulation, outcomes-focused regulation and strategies of enrolment, among others. ${ }^{6}$ Such forms of regulation are in competition with each other; and, as Casey and Scott pointed out quoting Black, are responses to an underlying legitimacy dilemma: it 'is simply not possible to have complete legitimacy from all aspects of [the regulated] environment'. ${ }^{7}$

In this tangled, contested field, and in place of a conservative view of regulation-as-oversight merely, I argue first that regulatory theory and practices applied to legal education should go beyond the basics of control of risk, management of compliance and protection of consumer interest to the development of regulatory relationship between stakeholders that will improve educational theory and practice. Second, I argue that, four years on from LETR and the articulation in that report of a 'shared space' approach to legal education regulation, we need that approach more urgently than before. In developing it we need to take account of multi- and inter-disciplinary approaches, and inter-jurisdictional approaches that consist of not just global best practices but the complex weave of global with local circumstance, local regulatory codes and local practices. Taking account of the cognitive, organisational and social contexts of regulation in this way helps us to understand what may succeed locally, and why. I give an extended example of this in development and practice from professional legal practice and regulation in Scotland. Finally, I shall argue that transformation of regulatory relationship cannot take place unless we have an informational and data structure that is commensurate with our ambitions for regulation in legal education. Throughout, there is an implicit argument for interdisciplinarity. I argue elsewhere in depth that interdisciplinarity is both conceptual and practical in nature. ${ }^{8}$ Too often we treat education and law in separate silos, without recognising the effect that one has on the other, and how our distinctive modes and discourses are formed from jurisdictional cultures - which include regulation. We also do not sufficiently recognise the advantages of interdisciplinarity in opening up the fractures in disciplines so as to enable expansive exchanges - what Foucault called, with regard to forms of rationality, the 'transmissions, transferences, interferences' between them. ${ }^{9}$

\section{Beyond standard-setting}

It goes without saying that regulation of legal education involves standard-setting in all aspects of the domain. But this is not the only activity that regulation could involve, and of itself it tends to be one of the negative virtues of regulation - the default position being that legitimate interests must be defended by maintaining or raising standards. Along with this, however, goes the view that regulation is a 'necessary evil', a notion that research indicated was 'widespread in the legal services sector' ${ }^{10}$ The sparse, standards-setting view of regulation and the corollary distaste for it (spilling over at times into hostility) among regulatees under regimes such as Outcomes-Focused Regulation (OFR), comes about as binary relational response that reinforces each polar position. ${ }^{11}$ It also

\footnotetext{
${ }^{6}$ For an account of these and other approaches, and their performance within the financial services industry in the recent global financial crisis, see Julia Black, Paradoxes and failures: "New governance" techniques and the financial crisis, 75 MOdern LAW ReVIEW 1037-63 (2012).

7 Donal Casey \& Colin Scott, The crystallization of regulatory norms., 38 JOURNAL OF LAW \& SOCIETY 76-95 (2011), 92, citing Julia Black, Constructing and contesting legitimacy and accountability in polycentric regulatory regimes, 2 REGULATION \& GOVERNANCE 137-164 (2008), 153.

${ }^{8}$ See for example Paul Maharg, Sea-change, 18 International Journal of the Legal Profession 139-64 (2012); Paul Maharg, Transforming Legal Education: Learning and Teaching the LaW in the Early Twenty-First Century (Ashgate Publishing) (2007)

${ }^{9}$ Michel Foucault, Politics, Philosophy, Culture: Interviews and Other Writings, 1977-1984 (L. Kritzman ed., A. Sheridan trans., Routledge) (1988), 36. It is useful to compare Foucault's concept of the fissures in forms of rationalities that enable transferences with Roberto Unger's concept of 'expanded discourse', developed in defence of a version of radical interdisciplinarity - Roberto Unger, The Critical Legal Studies movement, 96 HARVARD LAW REVIEW 561-675 (1983), 561. 10 Webb et al, supra, note 2 at 264.

${ }^{11}$ Webb et al, supra, note 17 at 87 describe OFR in the professional legal domain in England and Wales as follows: 'OFR Outcomes are [...] derived [...] from general principles of good regulation and the eight "regulatory objectives" specified by s.1, LSA [Legal Services Act] 2007 [...]. These apply to all aspects of the regulatory work of the Legal Services Board and
} 
depends on a view of good regulation as being either sufficient regulatory control, or minimalist control, that is to say, an absence of what both regulator and regulatee would both regard as a universal evil, namely over-regulation and over-monitoring.

Underpinning both sides in this binary is the assumption that regulation exists as a set of conditions and rules for those being regulated, and that the regulation framework needs to be fit for purpose. Defining purpose, however, is no easy matter given the often wide variety of legitimate interests that contest for priority; and this is true of every regulated domain. Even apparently obvious positions, such as zero-harm or the absence of accidents in the safety industries, are problematic when one begins to engage with theories of how accidents occur (eg risk compensation theory) and the psychology and context of actors and their networks of relationships. As John Adams points out in his analysis of the effects of anti-lock braking systems (ABS) on accident statistics,

When introduced, their superiority persuaded many insurance companies to offer discounts for cars with anti-lock brakes. Most of these discounts have now been withdrawn. The ABS cars were not having fewer accidents, they were having different accidents. Or perhaps they were having fewer accidents, but no fewer fatal accidents; the evidence from various studies is less than conclusive. ${ }^{12}$

The binary view may also take for granted that deterrence positions adopted by regulators works to deter types of behaviour, when in fact the conditions under which deterrence may actually succeed are complex, and the apparent obviousness of the assumption may blind even researchers to the subtle effects that deterrent regulation has upon actors. ${ }^{13}$

There is another view of regulation, however, that defines the field in which regulation operates as one of inescapable complexity, where every intervention by a regulator, or move by a regulated party makes the field more complex for the main actors and the legitimate interests of other players; and that this complexity goes unregarded by the parties involved, for often quite complex motives. Amongst a number of commentators on this, Sidney Dekker has produced what is perhaps the most interesting application of complexity theory to the situation. ${ }^{14}$

Before I outline some of the key traits of Dekker's approach it might be helpful to define what, in legal educational terms, Dekker would regard as a complex system. Dekker himself makes a helpful distinction between a complicated system and a complex system. A jet airliner is a complicated system, but nevertheless one that can be disassembled and re-assembled from its component parts, because it is 'understandable and describable in principle'. By contrast, complex systems work in real time; each component works with another but in local relation only, and the component or manufacturer of the component would be unaware of the behaviour of other components in realtime action, in multiple complex environmental contexts:

Jet airliners become complex systems when they are deployed in a nominally regulated world with cultural diversity, receiver-oriented versus transmitter-oriented communication expectations, different hierarchical gradients in a cockpit and multiple levels of politeness differentiation [...], effects of fatigue, procedural drift [...], varied training and language standards [...], as well as cross-cultural differences in risk perceptions, attitudes and behaviour [...]. This is where complicated systems become complex because they are

\footnotetext{
each of the frontline regulators. They are a significant innovation of the LSA 2007 and a key recommendation of the Clementi Review (2004)'.

12 Id., Literature Review, chapter 3 at 16, quoting MANAGING TRANSPORT RISKS: WHAT WORKS? PAPER FOR RISK THEORY HANDBOOK. (2010), available at http://www.john-adams.co.uk/papers-reports/ at 15 (last visited Jan 30, 2017).

${ }^{13} \mathrm{~A}$ classic study in this regard is that of $\mathrm{H}$. Laurence Ross on the effectiveness of drink-driving legislation in Sweden and Norway. H. Laurence Ross, The Scandinavian Myth: The Effectiveness of Drinking-and-Driving Legislation in Sweden and Norway, 4 THe Journal of Legal Studies 285-310 (1975).

${ }^{14}$ Sidney Dekker et al., The complexity of failure: Implications of complexity theory for safety investigations, 49 SAFETY SCIENCE 939-945 (2011), 942.
} 
opened up to influences that lie way beyond engineering specifications and reliability predictions. ${ }^{15}$

Dekker's example can be applied to the system of an educational programme, such as the professional legal education degree in Hong Kong, the PCLL. Described in depth on paper, as if one were seeking approval from a regulator, for instance, and the curricular, 2-D object of a PCLL curriculum is complicated, and will include purpose and learning outcomes, progression, certification level, curriculum structure, support for student work, recognition of prior learning, teaching methodologies, assessment design, summative assessment map, evaluation of programme and much else. But this complicated system becomes a complex system when it is run in real-time. Each component will then have interdependencies and interactions in complex contexts, where complex relations grow in time. For example what might appear to be a relatively simple example of feedback on task needs to dovetail with feedforward, and with summative assessment content and design. Through time and over a number of cycles, the system becomes more complex as components alter on the basis of student evaluation, compliance with changed regulation, staff turnover and other changes.

Inevitably, it becomes too complex a system for even the most detailed curriculum log to describe the micro-behaviour of each component in the system. Macro-events, then, such as regulatory oversight, monitoring visits or programme reviews, tend to simplify the complex interactions of micro-components, or deal with them in terms of narrative stereotypes, or tick-box comparators. Thus even programme staff who have most design knowledge will have only a partial view of the whole complex system, though they may make inflated knowledge claims in formal documentation; and this partial view leads to 'curriculum drift' (comparable to what Dekker calls 'procedural drift', but in disciplinary content as well as educational structure) where purpose and aims lose focus as component changes multiply and their effects become less controllable.

Educators can also be blind-sided by asymmetry of expertise. What appears to experts to be a reasonable way to understand complex law or process may be baffling to novices because experts assume knowledge or habitual practice, or move too fast, or miss key stages that to an experienced practitioner would be entirely taken for granted, but isn't so for novices. Paradoxically, what is true of students is also true of regulators, who nearly always have a lot less knowledge of the complex educational system under review, both content and structure, and rely on highly constrained instruments to obtain even that. And yet regulators, faced with monitoring multiple programmes and with a concern that required levels of competence for licensure are comparable across institutions and programmes, often are under pressure to set and enforce clear standards. Partly as a result of such multiple complexity and pressure, legal education regulators are increasingly retrenching from frontline regulation, and relying upon centralised assessments to ensure comparability, robustness, standardisation and reliability in assessment for licensure. ${ }^{16}$

\footnotetext{
15 Id.

${ }^{16}$ See for example the recent consultations upon a Solicitors Qualifying Examination, proposed by the SRA (see https://www.sra.org.uk/home/hot-topics/Solicitors-Qualifying-Examination.page , (last visited Jan 30, 2017)), and proposals by the Law Society of Hong Kong for a Common Entrance Examination (http://www.scmp.com/news/hongkong/law-crime/article/1898439/law-society-pushes-ahead-unified-solicitors-exam-2021, (last visited Jan 30, 2017)). This is true also in medical education, where the same direction by regulators has been under debate for some time now. See Julian Archer et al., The medical licensing examination debate, REGULATION \& GoverNANCE n/a-n/a (2016). The debate has been stimulated in part by the studies that show the complexity and difficulty involved in achieving comparable standards across institutions. See Joachim P. Sturmberg \& John Hinchy, Borderline competence - from a complexity perspective: conceptualization and implementation for certifying examinations, 16 JOURNAL OF EVALUATION IN CLINICAL PRACTICE 867-872 (2010). See also the series of studies carried out on comparative competence by Kathy Boursicot and colleagues Katharine Boursicot, Setting Standards in a Professional Higher Education Course: Defining the Concept of the Minimally Competent Student in Performance-Based Assessment at the Level of Graduation from Medical School, 60 HIGHER EDUCATION
} 
In these debates it is understandable that regulators seek to simplify the complexity of the objects of regulatory regimes, not just for themselves but for all concerned. And yet seeking simplicity will almost certainly lead to further problems. Dekker shows how complexity theory can assist us to understand complex systems and regulation:

1. In complex systems there is no clear 'relationship between component behaviour and system-level outcomes'.

2. In complexity theory claims that the isolation of a single narrative as a truth-narrative is impossible.

3. Research into both failure and success requires to piece together multiple perspectives in a complex system.

4. Multiple narratives in complex systems will be repetitious, rarely coherent, sometimes contradictory.

5. Narrative pluralism and diversity is not a fault: it gives us 'more opportunities for learning'. ${ }^{17}$ When seeking clarity by reducing complexity, then, regulatory monitoring may focus on individual components (eg objects such as technologies, or human errors or achievements) without seeing the complex social, cognitive, epistemological and organisational whole that gives rise to the situation. Sometimes, too, the regulatory focus on control, compliance and quantification of risk can narrow parties' range of vision about systems, and induce indulgence on the part of regulators, or loss of innovation edge and complaisance or superficial self-analysis on the part of the regulated. ${ }^{18}$

One alternative to regulation as standards-setting, and an alternative that may accommodate complexity theory, is a view of regulation that is more community-based than many regulatory discourses may permit. In the Legal Education and Training Report on professional legal education in England and Wales we characterised this approach as a 'shared space' approach to regulation, an approach I have since described in detail elsewhere, and applied to the specific topic of innovation and technology in legal education. ${ }^{19}$ Below I shall describe and analyse an instance where it began to form out of the necessities and opportunities that underpinned the formation a new professional curriculum in Scotland; and the relationship of gradual regulatory reform that grew around it.

\section{Regulation and relationship: professional legal education in Scotland}

\section{GGSL and the politics of curriculum development}

In 1999 I joined the newly-formed Glasgow Graduate School of Law (GGSL), which brought together most of the graduate programmes and all the professional programmes of the University of Glasgow Law School and the Strathclyde University Law School. A key task was to harmonise the two primary professional programmes, the Diplomas in Legal Practice, and to do so in line with a new plan for the Diploma set out by the Law Society of Scotland (LSS). ${ }^{20}$ Since the programmes had the same subjects, were taught by the same method of employing practitioner-tutors, and assessment by

\footnotetext{
QUARTERLY 74-90 (2006); and Katharine A M Boursicot et al., Using borderline methods to compare passing standards for OSCEs at graduation across three medical schools, 41 MEDICAL EdUCATION 1024-1031 (2007).

17 It is interesting to note how complexity theory and Dekker et al's use of it draws from narrative theory and narratology an example of the interdisciplinarity I discussed above.

${ }^{18}$ See Sidney Dekker \& Corrie Pitzer, Examining the asymptote in safety progress: a literature review, 22 INTERNATIONAL JOURNAL OF OCCUPATIONAL SAFETY AND ERGONOMICS 57-65 (2016)

${ }^{19}$ See Webb et al, supra note 2 at 268; Paul Maharg, Shared space: regulation, technology and legal education in a global context, 6 EuRopeAn Journal of LAW AND TeChNology (2015), http://ejlt.org/article/view/425 (last accessed: 30 Jan 2017). 20 This new approach emphasised professional skills, since an earlier brief review of the DLP had indicated that students were lacking in skills required by legal service providers. The new approach was outlined in a brief document: knowledge components were still expressed as aims and objectives, and skills were outlined in several pages. Little other information was given out.
} 
unseen written examination was largely the key mode of evaluation, I assumed that the task would be relatively simple. Within a matter of months it became clear that this was a naive assumption. There were strong and quite different local cultures at each university that reflected the different identities of the two law schools and their links with the profession; and these identities played out in the forms of teaching and learning that each programme had developed and wished to retain. The politics of the merger were complex; we fused what we could, but the strategy of attempting to bring the best of the two programmes together could not work optimally because each institution had a different notion of what 'best' actually looked like. Moreover the programmes were difficult to reconcile with each other because their curriculum drift could not be reconciled with a detailed regulated plan - control of the national curriculum by the LSS was relatively light-touch.

The only answer to a rapidly deteriorating situation was to develop a third way: to seize the initiative of the new institution, develop a concept of a new progamme with a new approach to learning, teaching and assessment. It quickly became clear that this also required a fresh approach to both the profession and to our regulator, the LSS. What the new GGSL programme looked like has been described elsewhere. ${ }^{21}$ Suffice to say for our purposes here that the DLP was constructivist in design, implemented active-learning innovations in curriculum design and the use of technologyenhanced learning. It began to draw upon professional practice programmes in other disciplines, and deploy them with digital resources.

All that meant liaising with many stakeholders including the profession; but above all, we also needed to see the new programme as it developed from a student point of view. I therefore asked two students to keep detailed journals of their experiences on the 28-week long programme. One stopped soon after, but the second completed an entire year of journaling. I interviewed the student several times during the process, and read sections of the journal while it was in progress. To reflect on the final journal was a sobering experience. At times what he described scarcely seemed to be the same programme, certainly as we had designed and implemented it. For example, when I thought I had designed cycles of activities in a Foundation Course that operated on skills cycles of tell-show-do-review, and left time for reflection, it was clear that this student (and others, to judge from his journal) had been flung into an alien form of learning with arrays of activities that often absorbed them, but left them bemused because there was little time to absorb their learning. And the 'show' component of the cycle clearly didn't work and was simply another form of 'tell'. In general the feedback from students on Foundation Course was very positive; but the granular experience of this student and others was another and quite complex narrative; and was telling a different story. As a result I redrafted and streamlined the design of the Foundation Course, and began a nine-month multimedia project on professional legal skills to script, shoot, organise production and post-production, and embed online workshops in the Course. The multimedia units were highly successful and are still in use at Strathclyde University Law School, 16 years later. They would not have come about, certainly in the form that they did, without detailed journal comment from the student.

\section{Curricular innovation and the Law Society of Scotland}

These experiences and many others convinced me that the design complexity of professional legal education at GGSL, which was fast proceeding with projects in digital education and in skills education that borrowed from other jurisdictions and disciplines, needed to be presented, discussed, analysed. Above all I needed to know what our regulator, the LSS, made of all this. As I said, their regulatory control was light-touch by comparison with other jurisdictions, for example control over the Legal Practice Course in England by the then regulator, the Law Society of England \&

\footnotetext{
${ }^{21}$ See for example Karen Barton et al., Authentic fictions: simulation, professionalism and legal learning, 14 CLINICAL LAW REVIEW 143 (2007); MAHARG (2007) supra note 8; Maharg (2012) supra note 8.
} 
Wales. While this was problematic when carrying out comparative work between two programmes, it had the significant advantage that it stimulated and cleared space for innovation and experimentation. Indeed we could not have achieved nearly as much as we did in the GGSL had we the same onerous regulatory regime as operated in the LPC in England - an observation that was made by LPC staff I met at conferences and workshops.

In 2002 I joined the main Education and Training Committee of the LSS, also serving on a number of sub-committees and working parties and as a consultant, and remained on committee till I left the jurisdiction in 2010. What became apparent early on was that while Education \& Training Committee was the main development forum, little happened to improve education at a granular level within DLPs. Instead the Committee's time was taken up with the development of new elements - a Professional Competence Course, and an Assessment of Professional Competence project, for instance. These were useful projects but it seemed to me that the DLP needed major reform, but that such reform could only take place with reform of the entire process of legal education in Scotland, from LLB right through DLP, two-year traineeship and continuing professional development. In addition it was clear that much of what DLP staff at every university learned about their teaching and design practices went unjournaled, unshared, and therefore forgotten. To parallel the idea of curriculum drift, and Dekker's 'procedural drift', it seemed that there was design drift, with each DLP centre still enacting versions of what it had, historically, construed professional education to be. Moreover there seemed to be little inter-jurisdictional awareness or interdisciplinary curiosity.

In 2005 the Law Society decided to carry out a fundamental review of professional education in Scotland. Their review during 2006-7 considered competing views of legal education (and for the first time used an inter-jurisdictional literature review), focused on setting standards, took account of the range of titles to practice as well as activities within practices and entities that practised in Scotland. It also took account of undergraduate LLB programmes in universities, as well as the continuing professional development of solicitors in practice. It focused also on issues of gender, equality and diversity. The jurisdiction-wide online and face-to-face consultation that took place was one of the most remarkable activities that Education \& Training Committee ever undertook, a courageous step for a small jurisdiction's regulator with limited resources at its disposal.

For my part, I contributed to a literature review on digital education and practices in other jurisdictions. On the basis of the feedback across the jurisdiction, I was also tasked to assist in writing a new set of outcomes and standards for replacements of the Diploma and Professional Competence Course, namely Professional Education And Training, 1 and 2. I wrote outcomes for the skills components of the PEAT 1 outcomes and assisted in the design of PEAT $2 .^{22}$ First the skills had to be defined, reading from my interpretation of the consultation data. In the process I drew upon years of design experience at the GGSL and before, as well as curriculum renewal papers I wrote for Education \& Training. At the forefront, though, were the data arising from qualitative and quantitative analysis of the consultation on values, principles, processes and content of professional legal education. Communication and partnership were seen as key to the future success of legal education in Scotland.

Within the remit of our working party we mapped out three key aspects to the new professional programme designs: transactional learning, professionalism and an open source economy that would function as - to adopt the title of Yochai Benkler's analysis of the networked information

\footnotetext{
22 Original documents on file with the author and the Law Society of Scotland.
} 
economy to the microcosm of legal education - a wealth of networks that would join up jurisdictions, regulators and single education providers. ${ }^{23}$ These are described in more detail below.

\section{Transactional learning}

This was an approach to learning that we developed in the GGSL to explain to explain to ourselves, our students and others what we were attempting to do in legal education. There were three aspects that were important, and which were mapped out from my reading of jurisprudential, educational and interdisciplinary educational writings. First, transactional learning focused upon legal transactions in the broadest sense - any form of process or representation by a lawyer on behalf of a client, in any area of law. ${ }^{24}$ Second, it denoted an educational approach to legal learning, and with seven traits:

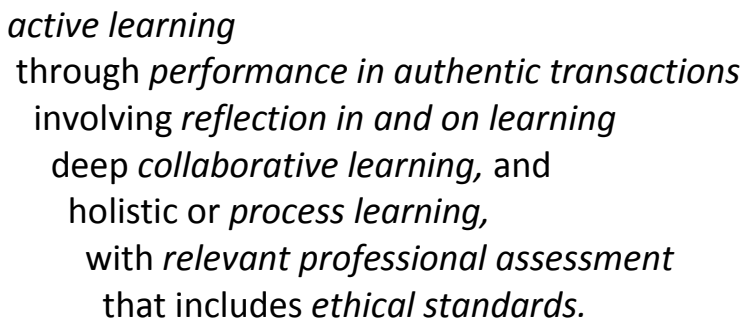

Third, it was shorthand for an approach to education and epistemology that was hermeneutic and phenomenological in its approach, where education was less a form of interaction with the world and more a transaction within the world. In this sense the approach was based upon Dewey's educational praxis, where educational and philosophical (or here, jurisprudential) inquiry was fundamentally the same activity. It is tempting to see these three layers of meaning as becoming more profound and complex as one moves from one through to three. But - and following complexity theory as well as Dewey's Pragmatist approach - a separation of the apparent dichotomies of superficial/practical from profound/theoretical makes no sense: theory is imbricated with practice; practice imbues theory. Transactional learning was thus not merely a handy heuristic for tutors or for PEAT 1 designers or to be used only in professional education - it was an approach to legal learning that was rooted in educational and jurisprudential discourse. ${ }^{25}$

\section{Professionalism}

There was, though, a need for a binding concept, once that could construct regulatory legitimacy for the LSS, and at the same time for DLP providers, including the GGSL, express the accountability and responsiveness of students, educational providers and the profession. When I considered the results of the LSS consultation, as well as my own experience at the GGSL, and on Education \& Training Committee, it was clear that throughout the jurisdiction there was no overall guiding

\footnotetext{
${ }^{23}$ See Yochal Benkler, The Wealth of Networks: How Social Production Transforms Markets and Freedom (Yale University Press) (2006). Benkler's title, of course, is another example of a book title answering an earlier book - in this case Adam Smith's The Wealth of Nations.

${ }^{24}$ In that sense the approach is profoundly Realist, in origin at least, and aligned with the New Legal Realism movement, which seeks to enact a Deweyan Pragmatist approach to understanding law's power in society. See Howard Erlanger et al., Is It Time for a New Legal Realism, 2005 WISCONSIN LAW REVIEW 335 (2005); Stewart Macaulay, The New versus the Old Legal Realism: Things Ain't What They Used to Be, 2005 Wisconsin LAW Review 365 (2005); Thomas J. Miles \& Cass R. Sunstein, The New Legal Realism, 75 THE UnIVERSITY Of CHICAGo LAw Review 831-851 (2008). A good example of its work is Elizabeth Mertz's study of discourse and power in US law schools that reveals how the critical shift from moral frameworks to apparently value-neutral legal frameworks occurs in law school classrooms. Her book is a classic study in sociolinguistics and legal anthropology, and a good example of how New Legal Realism, in its emphasis on researching how law and legal cultures affect the lives of all who come into contact with it, differs from the older, early twentieth-century forms of legal realism, which tended to focus more on the actors and processes of formal legal systems. ELIZABETH MERTZ, THE LANGUAGE OF LAW SCHOOL: LEARNING TO "THINK LIKE a LAWYER" (OUP USA) (2007).

25 See MAHARG (2007) supra note 8, especially chapters 7,8 and 9.
} 
concept for educational process. It was also clear that from an educational as well as a regulatory point of view, there had been no articulated approach to the links between educational theory and practice in Scottish professional legal education. Indeed the same could be said for legal education generally in Scotland. Law schools had made few sustained attempts to say to themselves, to students, regulators, funders, the profession, the general public, what they did in legal education and why. There were of course internal university documents, often produced for Quality Assurance purposes, which under the Scots system of learning enhancement had the distinct advantage of focusing on the institution's goals and means of attaining them. However these tended to be institutional documents, not rooted in the educational discourse of specific disciplinary forms of education or linked directly to regulatory practices of professional bodies.

My interest in professionalism as a binding concept for regulatory as well as an educational purpose had arisen from research questions generated by the literature - in a general sense, how was it that novices in a profession learned to be professionals? And how did this happen in what much of the research described as dislocated professional communities so characteristic of late capitalism? If we accept that, as practice theorists have it, practices are the 'source and carrier of meaning, language and normativity', and our understanding of practices cannot be separated from an understanding of the social context of the practices, then how does this affect our construction of educational processes for professional practice? Finally, how does professionalism contribute to the general concept of moral and ethical formation in our students; and could it be said that, as a core concept, it is too narrow and loaded to bear the weight of that formation?

Through our work at the GGSL, and in reading the literature in other disciplines, particularly medical education, it did seem that professionalism could provide an over-arching framework for our purposes in Scotland..$^{26}$ The work of Maxine Papadakis and her colleagues in medical education on evaluation of medical professionalism was particularly in point. With her permission we used her documentation at the GGSL to assist us evaluate the professionalism of novice lawyers. ${ }^{27}$

I therefore drew up a visual model for the mandatory core of the new PEAT 1 programme (Fig 1), where the previously lengthy curriculum core (which we agreed on LSS was problematic) was slimmed down, giving space for providers and students to construct and to participate in elective learning, integration with PEAT 2, and with the use of e-portfolios to help bridge the two programmes. The core of the two learning programmes was based upon professionalism, which later in the documentation was described as a spiral curriculum throughout the three-year period of professional legal education. ${ }^{28}$

\footnotetext{
${ }^{26}$ See for example the work of Karen Barton and Fiona Westwood on the relationships between learning and trust in groupwork within virtual firms, and which in part gave rise to their further work on the resonance of vocational learning. See Karen Barton \& Fiona Westwood, From student to trainee practitioner - a study of team working as a learning experience, 6 WEB JOURNAL OF CURRENT LEGAL ISSUES (2006),

http://www.bailii.org/uk/other/journals/WebJCLI/2006/issue3/barton-westwood3.html; Developing professional character - trust, values and learning, in AfFect And Legal Education: Emotion in Learning ANd TeACHing the LAW 235-56; The Calling of Law: The Pivotal Role of Vocational Legal Education (F. Westwood \& K. Barton ed., Routledge) (2016). In medical education the debates around professionalism have been vigorous and contested, and have provided legal educators with models and arguments that can be applied to legal education.

27 Maxine A. Papadakis et al., Unprofessional behavior in medical school is associated with subsequent disciplinary action by a state medical board, 79 Academic Medicine: Journal of the Association of American Medical Colleges 244-249 (2004). See also Peggy Wagner et al., Defining medical professionalism: a qualitative study, 41 MEDICAL EDUCATION 288-294 (2007). 28 Documents on file with the author and the LSS. It should be noted that these diagrams and tables are of historical value: they are early drafts of what later became the formal PEAT programmes, and are now no longer current practice on the LSS professional programmes, though of course they have contributed to the development of current practice. In an earlier draft of the tables I included negative as well as positive indicators.
} 


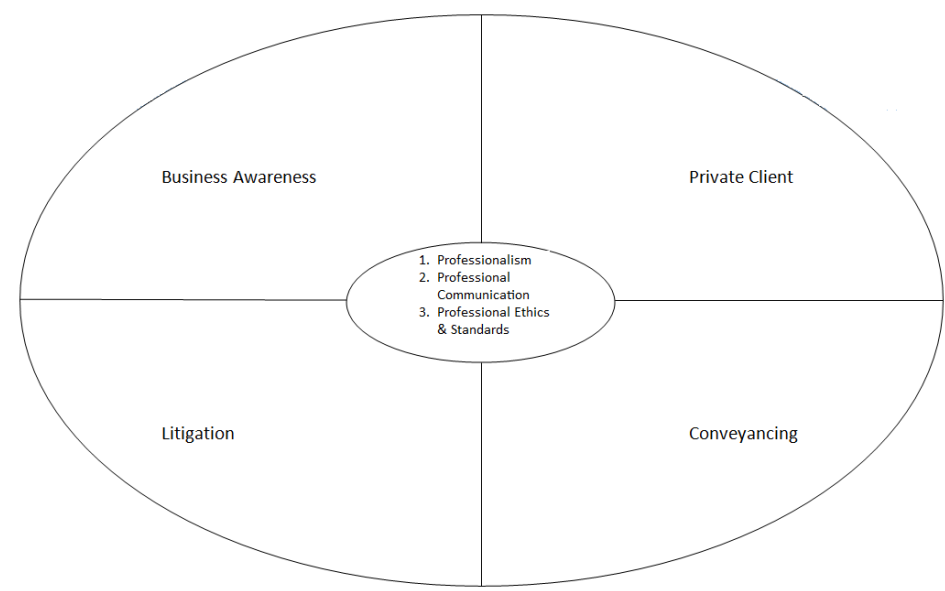

Figure 1: Mandatory core of the PEAT 1 programme

Upon this model the new framework for the period of the two-year traineeship and its education was based, namely PEAT 2 (Fig 2):

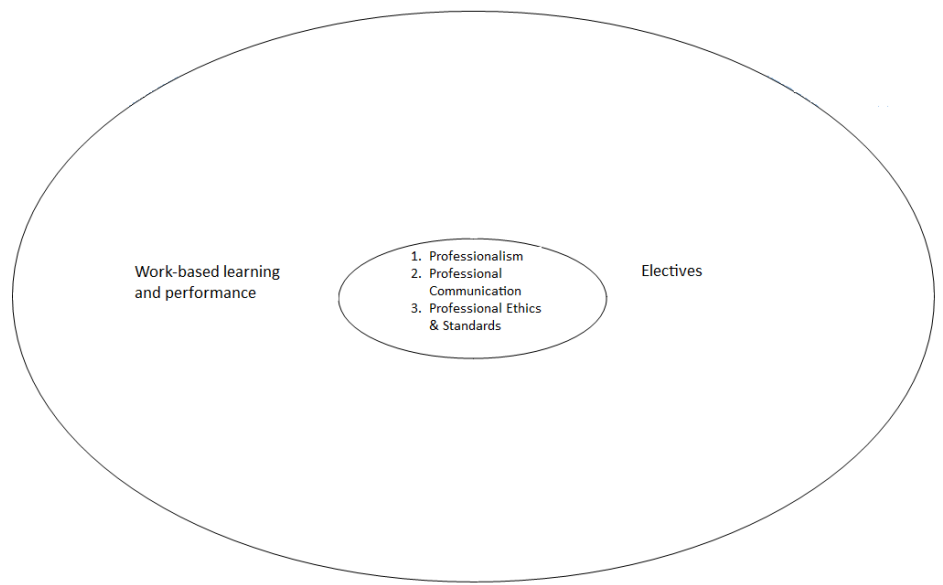

Figure 2: PEAT 2 basic framework

Professionalism, a major domain for the programme, was defined less as outcomes and more as a commitment to a range of values, tasks, skills and traits outlined in Fig 3:

\begin{tabular}{|c|c|c|c|}
\hline $\begin{array}{l}\text { Major } \\
\text { domain }\end{array}$ & 1. Professional & & \\
\hline $\begin{array}{l}\text { Minor } \\
\text { domain }\end{array}$ & $\begin{array}{l}\text { Throughout the } \\
\text { programme a } \\
\text { student should } \\
\text { demonstrate a } \\
\text { commitment to: }\end{array}$ & Positive indicators & $\begin{array}{l}\text { Appropriate forms of } \\
\text { assessment }\end{array}$ \\
\hline 1. & $\begin{array}{l}\text { The interests of } \\
\text { justice and } \\
\text { democracy in } \\
\text { society }\end{array}$ & $\begin{array}{l}\text { Displays an interest in the workings of justice in } \\
\text { society; has an ethical awareness of legal practice, } \\
\text { and a developing sense of the regulatory framework } \\
\text { of professional ethics. Shows awareness of his or } \\
\text { her responsibility to improve the capacity of legal } \\
\text { institutions and process. }\end{array}$ & $\begin{array}{l}\text { Best assessed longitudinally } \\
\text { throughout the programme, by } \\
\text { more than one assessor, and in } \\
\text { more than one assessment, so } \\
\text { that a variety of views are } \\
\text { obtained under different }\end{array}$ \\
\hline
\end{tabular}




\begin{tabular}{|c|c|c|c|}
\hline 2. & $\begin{array}{l}\text { Effective and } \\
\text { competent legal } \\
\text { services on behalf of } \\
\text { a client }\end{array}$ & $\begin{array}{l}\text { Updates and expands knowledge of the law, } \\
\text { knowledge of legal practice, client-centred practice } \\
\text { and management of client service. Pays careful } \\
\text { attention to standard of detail in legal work; evaluates } \\
\text { own client care; appraises new forms of client care } \\
\text { and adopts improvements; acts quickly to protect } \\
\text { clients and the public from risk. }\end{array}$ & \multirow{4}{*}{$\begin{array}{l}\text { conditions. Providers should be } \\
\text { under an obligation to inform } \\
\text { the Society of students who } \\
\text { obtain problematic scores in } \\
\text { any of the minor domains. } \\
\text { Forms of assessment could } \\
\text { include: } \\
\text { 1. Client-based long case } \\
\text { 2. Case file review of } \\
\text { simulated client file } \\
\text { 3. Portfolio - self-assessment } \\
\text { 4. Log book/activity } \\
\text { 5. Critconfidential file } \\
\text { 6. Peer-review } \\
\text { 7. Transactional assessment } \\
\text { 8. Tutor reports }\end{array}$} \\
\hline 3. & $\begin{array}{l}\text { Continuing } \\
\text { professional } \\
\text { education and } \\
\text { personal } \\
\text { development }\end{array}$ & $\begin{array}{l}\text { Is aware of own strengths and weaknesses and } \\
\text { forms plans to develop character, values, knowledge } \\
\text { and skills throughout the course. }\end{array}$ & \\
\hline 4. & $\begin{array}{l}\text { Diversity and public } \\
\text { service }\end{array}$ & $\begin{array}{l}\text { Shows an awareness of the importance of equality of } \\
\text { access to and participation in legal services } \\
\text { regardless of culture, race, religion, gender, } \\
\text { disability; assists in the training of new lawyers } \\
\text { through peer learning and training of undergraduate } \\
\text { students or other groups in society. }\end{array}$ & \\
\hline 5. & $\begin{array}{l}\text { Personal integrity } \\
\text { and civility towards } \\
\text { colleagues, clients } \\
\text { and the courts }\end{array}$ & $\begin{array}{l}\text { Is honest with all others on the course; relates to } \\
\text { colleagues on the programme with civility; treats } \\
\text { tutors, administrative staff and others with respect. }\end{array}$ & \\
\hline
\end{tabular}

Figure 3: Professionalism values and traits.

Finally, skills were envisaged less as free-standing behavioural components, which they are in other legal educational regulatory codes, and were dovetailed into the professionalism framework and were interleaved with each other as communicational skills. They consisted of the following:

1. Professional relationships

2. Interviewing

3. Negotiation

4. Writing and drafting

5. Transactional research

6. Use of technology

7. Advocacy

The skills were designed to interlock with the basic concepts of transactional learning and professionalism. Thus professional research was defined as transactional research, and the two out of seven total outcomes for the minor domain (Fig 4) illustrates how they were defined:

\begin{tabular}{|c|c|c|c|}
\hline $\begin{array}{l}\text { Major } \\
\text { domain }\end{array}$ & $\begin{array}{l}\text { 2. Professional } \\
\text { Communication }\end{array}$ & & \\
\hline $\begin{array}{l}\text { Minor } \\
\text { domain }\end{array}$ & $\begin{array}{l}2(v) \text { Transactional } \\
\text { research } \\
\text { By the end of the } \\
\text { programme students } \\
\text { should be able to: }\end{array}$ & Positive indicators & Appropriate forms of assessment \\
\hline 1. & $\begin{array}{l}\text { Gather information } \\
\text { relevant to a matter }\end{array}$ & $\begin{array}{l}\text { Can obtain factual } \\
\text { information and methodically } \\
\text { record the varieties of } \\
\text { information and their sources } \\
\text { (paper document, oral, } \\
\text { electronic) for future } \\
\text { analysis; can plan work to } \\
\text { research deadlines. }\end{array}$ & $\begin{array}{l}\text { Assessment by performance is essential in } \\
\text { this skill. It should be in as realistic a situation } \\
\text { as is feasible for providers. Assessment } \\
\text { should also be embedded where possible } \\
\text { within programme modules or projects, rather } \\
\text { than in stand-alone assessments. The } \\
\text { following forms of assessment are } \\
\text { recommended: }\end{array}$ \\
\hline 2. & $\begin{array}{l}\text { Analyse and } \\
\text { prioritise factual } \\
\text { issues }\end{array}$ & $\begin{array}{l}\text { Can identify gaps, } \\
\text { ambiguities and } \\
\text { contradictions in information; } \\
\text { knows how to find further or } \\
\text { better information; can } \\
\text { prioritise legally important } \\
\text { facts. }\end{array}$ & $\begin{array}{l}\text { 1. Checklist of skills with allocation of marks } \\
\text { or standards } \\
\text { 2. Simulated casework research tasks, } \\
\text { assessed by tutor. } \\
\text { 3. Case file review by tutor } \\
\text { 4. Portfolio, in which students record } \\
\text { progress } \\
\text { 5. Open-book examination } \\
\text { 6. Objective structured case examination } \\
\text { 7. Critical incident review } \\
\text { 8. Transactional assessment }\end{array}$ \\
\hline
\end{tabular}

Figure 4: Transactional research outcomes (extract) 


\section{Open Education Resources (OER)}

At the GGSL and in my work with the LSS it quickly became apparent that innovation would only disseminate if education providers worked collaboratively with each other, and treated their programmes as learning laboratories, and extended that to the entire jurisdictional curriculum. We also needed an infrastructure that drew in a regulatory regime that promoted outcomes-focused regulation and encouraged collaboration and the sharing of educational resources and the costs of innovation, and rigorous research on educational practices and achievements.

At a meeting at Ross Priory (a retreat house belonging to Strathclyde University), therefore, the GGSL proposed this approach to PEAT 1 providers and the LSS. I followed that up with a paper and presentation at a UKCLE conference on Scots professional legal education in Edinburgh. Along with that, some of our innovations in virtual simulations that formed the core of our transactional learning at the GGSL were made available via a HEA and JISC funded Open Education Resources (OER) project called SimShare. ${ }^{29}$ The simulations themselves ran up on open-source software called SIMPLE (SIMulated Professional Learning Environment), which was developed in a two-year project with a range of law schools and other disciplines throughout the UK, and funded by HEA and JISC. ${ }^{30}$ Another innovation was the use of standardised or simulated clients - adapted from medical educational practice, it involved lay persons being trained to simulate a client narrative, and to assess the client-facing skills of a novice lawyer. ${ }^{31}$ This approach was adapted for the development of the SRA's Qualifying Lawyers Transfer Scheme (QLTS), and has been developed in at least a dozen other centres globally. ${ }^{32}$ The documentation that we developed is licensed under a Creative Commons licence, freely available for non-commercial use.

\section{Shared space and regulation of legal education}

The experience of developing these initiatives and of working productively with the LSS fed into the LETR project on regulation. There, the regulatory shared space of legal education, derived from a number of disciplines and from the consultation data too, is the idea that regulation is too important to be left only to regulators, and that it is the responsibility of all stakeholders to share in it: to share their educational practices, the evaluation data they generate as well as their research, and to engage in mutual learning, transparently and openly. It gives responsibility to actors in the regulated field to regulate their own behaviour, subject of course to monitoring. It is a dynamic concept, and challenges regulators as much as providers and others. Regulatory activity, rather than directly changing behaviour, may well merely ratify already-established practices and opinions; and this effect can be mitigated by giving actors freedcom to act in the field. In addition a shared space allows for innovation to be disseminated, critiqued, improved much faster, and for the design \& implementation cycle to be made more effective. LETR suggested that it is the responsibility of

\footnotetext{
29 Julian Priddle et Al., Simshare: Project Final Report (UKCLE) (2010), available at http://www.synergese.co.uk/PDF/115649_SimShareReport_final.pdf (last accessed 30 Jan 2017). The project website, the design of which was a core element of the project, was completed and the report was deposited with JISC.

${ }^{30}$ Information on the SIMPLE project on the JISC site is available at: https://www.webarchive.org.uk/wayback/archive/20140614100650/http:/www.jisc.ac.uk/whatwedo/programmes/elearni nginnovation/simple.aspx (last accessed 30 Jan 2017). A video of students talking about the project is available at: https://www.youtube.com/watch?v=myBSKs3-FTU (last accessed 30 Jan 2017).

31 See the original correlative study: Karen Barton et al., Valuing what clients think: Standardized clients and the assessment of communicative competence, 13 CLINICAL LAW REVIEW 1-66 (2006).

${ }^{32} \mathrm{See}$, for instance, Wilson Chow \& Michael Ng, Legal education without the law - lay clients as teachers and assessors in communication skills, 22 International Journal of the Legal Profession 103-125 (2015).
} 
regulators to design the space for this to happen, and in ss6.142-160 of the Report the authors mapped out how this might be designed.

Such a shared space also needs an information space and infrastructure for all stakeholders. Very few legal education regulators have archives of documentation that could be used to construct a history of modern and contemporary legal education in their jurisdiction. Nor is this a matter for regulators alone: in our discipline of legal education, we researchers have a poor record when it comes to organisation of data. Indeed our research informational infrastructure is in need of significant repair: without better information about what works and why in legal education and its regulation the process of regulatory reform is made more difficult. By contrast medical education is highly organised in its forms of research publication and in the forms of research analysis, for example in the production of meta-reviews, systematic reviews of primary research, and the like. Published research is regularly summarised for policymakers and regulators, and this enhances synergistic information exchange among stakeholders.

In one sense there is little new in this approach of the shared space. Commentators on regulation since the 1980s have argued that the deterrent effect of legal sanctions in command-and-control models of regulation do not of themselves prevent harm or dysfunction. Stone advocated that a regulatory framework should be employed to generate normative commitments within an institution or corporation via the organisation's internal systemics, and the shared space approach builds on this to create networks of collaborative activity between actors. ${ }^{33}$ Yet it also a radical approach. For the implication of the shared space is that it opens up regulatory control to democratic, shared responsibility for all. It acknowledges that there is no grande récit nor is there any 'grand solution' to the problems of regulation in legal education. ${ }^{34}$ Instead there are, as Dekker and others point out, multiple narratives of regulation, change, standards, and much else that need to be heard, analysed and acted upon.

There are narratives beyond regulation that illuminate out dilemmas. In Arrian's Life of Alexander the story of Alexander's encounter with the Gordian Knot is one of power and legitimacy, where according to prophecy, solving or untying the knot conferred upon the solver the lordship of all Asia. The knot bound ox-yoke, draw-pole and pin to an ox-cart, itself a holy object of earlier prophecy, and placed in a temple within the city of Gordium, in Phrygia. Alexander, we are told, untied the complex knot by slashing the tough rope of cornel bark with his sword. But in a lesser-known variant of the narrative Alexander did not use his sword: he removed the pin that secured the yoke to the cart-pole, enabling him to find the rope-ends hidden within the knot and thus to untie it. ${ }^{35}$

The competing, complementary narratives are an instance of Dekker's application of narrative theory to regulation. He would probably argue that neither is a truth-narrative, and that both contribute to our understanding - of Phrygian culture, of the power of prophecy, of the conflicting perception of Alexander's character, and much else. For us in our time and place they are also examples of two modes of regulation, one an adversarial and command model, the other a more extensive analysis of complexity and a more adaptive solution based upon it. The implication of power is analogous too, and is bound up with the occasion of regulation. Standing in front of the oxcart, and with everyone present knowing of the prophecy and watching, Alexander could not afford to fail the occasion. Nor can regulators now, authorised to regulate. Nor can we, the regulated, for regulation is critical to legal education and our working lives. Its effects and their consequences are

\footnotetext{
33 See Christopher D. Stone, Where the law ends: The social control of corporate behavior (Harper \& Row) (1975). See further Gunther Teubner, Substantive and Reflexive Elements in Modern Law, 17 LAW \& SOCIETY REVIEW 239-285 (1983); CHRISTINE Parker, The Open Corporation: Effective Self-regulation and Democracy (Cambridge University Press) (2010).

34 Julia Black supra note 7.

${ }^{35}$ Arrian et Al., The Campaigns of AleXander (B. Radice ed., A. D. Selincourt trans., Penguin Classics Revised \& Enlarged Edition edition) (1971), 105-6.
} 
substantial and far-reaching for teachers, institutions, students and the legal professions, and for society beyond the profession. Every day we face the Gordian knot. In response, do we acquiesce in, compromise with, manipulate, avoid or defy regulatory power that reaches almost all aspects of what we do ? $^{36}$

Bernstein's words quoted in the epigraph above point to how such power operates through symbolic control via 'pedagogic modalities'. As researchers have shown, it goes deep: it shapes forms of 'consciousness, identity and desire', through command and fiat as well as control of symbols and it claims to do so on behalf of legitimate social interests that are defined for the regulator by higher democratic agencies. But if the power to accredit, monitor, shut down is all that regulation consists of, it will be a reductive and ineffective form of regulation for education. I argue here for forms of regulation that will facilitate, enhance, encourage individual responsibility and community, and assist the understanding of complexity through open resources and methods. These are by no means the only approaches that regulators should take, but to date they have been under-used and under-researched in the regulation of legal education.

36 The modalities described here derive from Christine Oliver, Strategic responses to institutional processes, 16 THE ACADEMY OF MANAGEMENT REVIEW 145-79 (1991). Black, supra note 7, observes that they need refined and I agree, but they are a useful starting point for any consideration of the behavioural options facing those under regulation, particularly controland-command regulation with little sense of community. 